REVISTA DE DERECHO UNED, NÚM. 14, 2014

\title{
ALTERNATIVAS A LA JUDICIALIZACIÓN DE LOS CONFLICTOS DESDE ROMA HASTA LA ACTUALIDAD
}

\author{
ALTERNATIVES IN THE JURIDIFICATION OF CONFLICTS \\ FROM ROME TO PRESENT TIME \\ Joana Canet Sastre \\ Abogada en ejercicio \\ Ilustre Colegio de Abogados de Alicante
}

Resumen: Podemos observar como el sistema judicial actual en su aplicación práctica causa ciertas disfunciones generadoras de sufrimiento. Entendemos la existencia de crisis de legitimidad del sistema existente, por cuanto evidencia, su incapacidad para dar una respuesta satisfactoria a los requerimientos de la colectividad. Así se buscan alternativas a la judicialización de los conflictos. Las denominadas Prácticas Restaurativas que cuentan con una larga tradición, se estructuran más recientemente como un modelo de justicia, «la Justicia Restaurativa» que presenta ventajas de su uso entre las partes del conflicto. Esta denominada Justicia Restaurativa establecida, por lo general, para la resolución de conflictos de índole penal, en una óptica más amplia de la «restauración», permite pensar en la posibilidad de incorporar las prácticas restaurativas en la resolución de conflictos no solo de esta índole, sino también, a situaciones de la vida cotidiana, sea familia, iglesia, escuela, u otros, ya que culturalmente en todos los países existen mecanismos que buscan la resolución de conflictos de una forma no violenta. Ahora bien, la búsqueda de alternativas a la vía judicial, no ha de suplir el sistema judicial existente, sino ha de complementarlo, humanizarlo y racionalizarlo. Las Prácticas Restaurativas se han definido como una filosofía o un movimiento orientado a la conciliación antes que a la imposición de una sanción o pena de carácter retributivo. En Espa-

(C) UNED. Revista de Derecho UNED, núm. 14, 2014 
ña, el mecanismo alternativo al judicial extendido es el de la Mediación, introducida por la mediación familiar en la Ley 15/2005, de 8 de julio, por la que se modifican el Código civil y la Ley de Enjuiciamiento civil en materia de separación y divorcio, y en la que por primera vez en el ámbito procesal civil se incluyen normas concretas que albergan el sometimiento a mediación de determinadas cuestiones en materia de familia.

Palabras clave: Justicia restaurativa, diálogo, comprensión, perdón, reparación del daño, reconciliación.

Abstract: We can see how in practice the current legal system causes certain dysfunctions generated by suffering. Its inability to give a satisfactory answer to the needs of the community is evidence of a crisis of legitimacy of the existing system. Therefore, alternatives to the juridification of conflicts are sought. The so called Restorative Practices, that have a long tradition have most recently been structured as a justice model, "Restorative Justice», use of which has advantages among the conflicting parties. This so-called Restorative Justice which has been established, usually used to resolve criminal conflicts, in a broader «restoration» perspective, suggests the possibility of incorporating restorative practices in the resolution of conflict, not only of this kind but also for everyday life situations, be it family, church, school, or other, since culturally there exist mechanisms in all countries that seek to resolve conflict in a nonviolent manner. However, the search for alternatives to the courts, must not replace the existing legal system, but must complement, humanize and rationalize it. Restorative Practices are defined as a philosophy or a movement oriented towards conciliation before the imposition of a sanction or remunerative penalty. In Spain, the alternative to the legal mechanism sis Mediation, introduced by family mediation in Law $15 / 2005$ of $8^{\text {th }}$ July, amending the Civil Code and the Code of Civil Procedure in terms of separation and divorce, and for the first time in civil procedure include specific rules that contain the submission of certain issues to mediation in family matters.

Keywords: Restorative Justice, dialogue, understanding, forgiveness, reparation of damage, reconciliation.

Recepción original: 12/02/2014

Aceptación original: 10/03/2014

Sumario: I. Introducción. II. Solución de antigua Roma. El arbitraje. III. La justicia restaurativa. IV. Prácticas restaurativas. V. La mediación. VI. La mediación penal en delitos de violencia de género. 
VII. Propuesta de modificaciones legislativas para acoger la mediación penal en la legalidad sustantiva y procesal. VIII. Conclusiones.

\section{INTRODUCCIÓN}

En la actualidad el aparato judicial y legal no se ajustan a las necesidades de resolución que tienen los conflictos interpersonales suscitados en la sociedad. Esto desemboca en la imposibilidad de dar una respuesta concreta a la demanda social con la consecuente deslegitimación para la institución judicial.

Esta crisis puede ser superada o complementada, por la justicia restaurativa en muchos de los casos. La justicia restaurativa, a través de sus diferentes mecanismos, puede aportar respuestas alternativas que consigan una mayor comprensión, reparación, perdón y reconciliación entre las partes implicadas en un proceso.

\section{SOLUCIÓN DE CONFLICTOS EN LA ANTIGUA ROMA. EL ARBITRAJE}

En los primeros tiempos de la comunidad política romana, con anterioridad a la organización de la administración de la justicia y de la atribución de competencias a magistrados y jueces, la decisión de las controversias entre los particulares se encargaría a uno o varios árbitros, elegidos de común acuerdo por los interesados en solucionar sus conflictos ${ }^{1}$.

Bien podría considerarse esta solución de conflictos como un antecedente a lo que en la época moderna y sobre todo a partir de la década de los ochenta del movimiento llamado, «Justicia Restaurativa».

Según la tradición, la más antigua organización conocida de las relaciones de Roma con ciudades vecinas y pertenecientes a su mismo ámbito cultural y lingüístico, habría sido la federación denominada Liga Latina, que se remonta la época monárquica y que se habría reconocido por Spurio Casio en la República, el año 493 a. C., mediante el llamado Tratado o Foedus Cassianum, conforme al testimonio de Dionisio de Halicarnaso. Pues bien, en dicho tratado se contienen disposiciones reguladoras de los litigios surgidos entre miembros

${ }^{1}$ Vid., Fernández de Buján, A, «Derecho Público Romano», Recepción, Jurisdicción y Arbitraje. Capítulo XXII. 10. a edición. Thompson civitas 2007. 
de las distintas comunidades, que se producirían especialmente en el marco de las relaciones comerciales, y que en esta normativa (reciperatio), al igual que en la correspondiente a la configuración de los tribunales de recuperatores, se hace referencia al nombramiento de árbitros.

Es probable que el arbitraje, conocido y practicado en el ámbito del comercio internacional, se habría introducido en los mercados de la Roma de los primeros tiempos en los que los árbitros, serían, a la vez garantes y peritos y actuarían dirimiendo conflictos que se planteaban en el tráfico mercantil.

De este modo el arbitraje habría cumplido en los primeros siglos de Roma, conforme a las referencias contenidas en textos jurídicos y literarios, un importante papel, al igual que sucedía en otras comunidades políticas, no solo como complemento o alternativa a la jurisdicción, sino como instrumento de resolución de controversias, más allá de la autodefensa o autoayuda, por parte de un tercero imparcial, el arbiter, elegido de común acuerdo por las partes interesadas.

El término latino arbiter que derivaría de la lengua fenicia y haría referencia a garantía conforme a la raíz fenicia $r b n$, se habría introducido a través del comercio en la lengua latina.

El mantenimiento del arbitraje como técnica de resolución de conflictos en siglos posteriores, en los que se conoce la fórmula del proceso ordinario de impronta estatal, se explica por razones de rapidez, economía, sencillez en la tramitación, especialización en muchos casos del árbitro, no obligatoriedad de la condena pecuniaria etc., frente a la lentitud y formalismo del proceso oficial que, en contrapartida, presenta evidentes ventajas en materia de seguridad jurídica y efectividad en el cumplimiento de la sentencia.

En cuanto a los tipos de arbitraje, a grandes rasgos, y con el riesgo que supone toda esquematización de instituciones, no contenida en las fuentes romanas, cabría distinguir los siguientes tipos de arbitraje:

a) Arbitraje no formal: consistiría en un mero pacto, no protegido por el pretor ni por la ley, que no produciría consecuencias jurídicas inmediatas y que se movería en el campo, por otra parte relevante, de la fides y de la moral.

b) Arbitraje del ius gentium: era el correspondiente a la resolución de conflictos surgidos en la interpretación o aplicación de los pactos contraídos entre extranjeros y ciudadanos romanos entre sí, no previstos por el ius civile, pero si reconocidos por el 
ius pretorium, a través de la vía de los mecanismos procesales de la denegatio y la exceptio actionis.

c) Arbitraje legal: así denominado por estar previsto en la legislación de las XII Tablas o en leyes posteriores.

d) Arbitraje compromisario: también denominado merum arbitrium, que tenía en Derecho Romano un marcado carácter contractual. Consistía en el pacto o compromiso, y de ahí el hecho, de someter la resolución de un conflicto inter partes a la decisión de un árbitro, el cual se compromete a dar su opinión sobre el asunto. A dicho pacto se añadían estipulaciones recíprocas, generalmente con cláusula penal, para el caso de no colaboración con el árbitro en el desarrollo de su actuación o de no acatamiento de la sentencia o laudo arbitral ${ }^{2}$. Este tipo de arbitraje es el que en mayor medida ha influido en el arbitraje de Derecho moderno, conforme su ordenación legal en la Ley de Arbitraje de 1953, derogada por la ley de Arbitraje de 1988.

\section{LA JUSTICIA RESTAURATIVA}

Actualmente existe una gran confusión terminológica y conceptual para definir el nuevo paradigma de la Justicia Restaurativa, lo que ha dado lugar a una gran variedad de términos como justicia positiva, pacificadora, reparativa, restauradora, comunitaria, entre otros.

Se entiende como Justicia Restaurativa, el proceso que involucra a las personas afectadas de forma más directa por un delito o infracción, en la determinación de la mejor manera de restaurar la armonía social y dar solución al conflicto, considerando las necesidades y pretensiones de la víctima y del victimario. Es un modelo de justicia que busca establecer una relación justa y equilibrada entre las partes, para alcanzar la restauración de relaciones sociales quebrantadas por la comisión de un hecho ilícito, facilitando la oportunidad a las partes para expresar sus emociones y sentimientos, originados a partir del hecho ofensivo, así como una participación activa y directa en el proceso, dándole un rostro más humano a la justicia penal.

Esta denominada Justicia Restaurativa establecida, por lo general, para la resolución de conflictos de índole penal, en una óptica más amplia de la «restauración», permite pensar en la posibilidad de in-

${ }^{2}$ Es la regulación de este tipo de arbitraje compromisario, contenido básicamente en D. 4.8. «Sobre los casos de responsabilidad asumida. Que los que asumieron un arbitraje dicten sentencia». 
corporar las prácticas restaurativas en la resolución de conflictos no solo de esta índole, sino también a situaciones de la vida cotidiana, sea familia, iglesia, escuela, u otros, ya que culturalmente en todos los países existen mecanismos que buscan la resolución de conflictos de una forma no violenta.

En el último cuarto del siglo XX se inicia un cambio de sensibilidad respecto a la forma que debe tener la justicia a fin de responder a las necesidades de las víctimas, a la reinserción de los infractores y al papel de la comunidad en el proceso de administrar justicia. Algunos sociólogos y criminólogos como Nils Christie ${ }^{3}$, señalan que el Estado se ha adueñado de los delitos, convirtiendo el delito en un crimen contra las leyes del estado, dejando al margen a la víctima y a la comunidad y dificultando que el delincuente tome conciencia del daño causado. Otros, como el filósofo Randy Barnett (1977) proponen un cambio de paradigma en la justicia, hacia un sistema restitutivo (restitutional system).

A través de la justicia restaurativa se pretende:

1. Invitar al consenso y participación.

2. Sanar lo dañado.

3. Buscar completa y directa responsabilidad.

4. Reunir lo que ha sido dividido.

5. Fortalecer a la comunidad como tal, para prevenir daños mayores.

En nuestro sistema occidental, el paradigma de justicia que se sigue es el retributivo, el cual se basa en dos parámetros. Por una parte, el carácter retributivo de la pena y por otra parte el carácter reinsertador de la misma. En la realidad la retribución no siempre se produce y en menor medida si cabe la reinserción. Esto hace que nos planteemos la necesidad de otro sistema de Justicia.

Ahora bien, sin desconocer las inmensas cualidades y potencialidades de la Justicia Restaurativa, hemos de considerar que ésta puede perfectamente complementar a la Justicia Retributiva, pero nunca debería sustituirla. La Justicia Retributiva tiene lugar en circunstancias políticas y sociales excepcionales y enfrenta crímenes que en ocasiones atentan contra el núcleo más básico de la dignidad del ser

${ }^{3}$ Christie NiLs: (1977). Conflicts as Property. British Journal of Criminology. 17: 1-15. Hay una traducción castellana a la que se puede acceder en http://neopanopticum.blogspot.com/2005/11/christie-nils-los-conflictos-como.html. 
humano. Por el contrario, la Justicia Restaurativa fue diseñada para afrontar, en sociedades pacíficas la criminalidad de pequeña escala. Así, mientras que para este tipo de casos es plausible concebir el perdón y el olvido como estrategias eficaces para superar el crimen, para los casos de violaciones masivas de derechos humanos, una fórmula basada exclusivamente en perdones «amnésicos» no parece factible jurídica y políticamente, y ciertamente cuestionable éticamente ${ }^{4}$.

\section{PRÁCTICAS RESTAURATIVAS}

Las Prácticas Restaurativas se han definido como una filosofía o un movimiento orientado a la conciliación antes que a la imposición de una sanción o pena de carácter retributivo. En consecuencia, se centra en la reparación del daño y en la reconciliación de las comunidades de una manera tal, que lo que importa no es el castigo, sino reparar las relaciones que se dañan a partir de un conflicto, de una conducta que infringe los acuerdos de una comunidad o por la comisión de un delito.

La diversidad de prácticas y programas restaurativos incluyen, entre otros, a los Programas de Reconciliación Víctima y Ofensor o VORP (Victim-Offender Reconciliation Programs), desarrollados principalmente en Estados Unidos y Canadá, La Mediación Penal desarrollada en Europa, Las Conferencias del Grupo familiar de Nueva Zelanda, las Conferencias Comunitarias en Australia, los Paneles Juveniles en Inglaterra y Estados Unidos, y los Círculos comunitarios en Canadá.

\section{Programas de Reconciliación Víctima y Ofensor (VORP)}

El primer Programa de Reconciliación entre víctima y delincuente comenzó como un experimento en Kitchener, Ontario, a principios de los 70 cuando un funcionario de libertad condicional de menores convenció a un Juez de que dos jóvenes condenados por vandalismo debían reunirse con las víctimas de sus delitos. Después de los encuentros, el Juez ordenó a ambos jóvenes realizar una restitución a las víctimas como condición para la obtención de la libertad condicional. Por lo tanto, los VORP comenzaron como una sentencia alternativa posterior a la condena basada en la libertad condicional, inspirada en

${ }^{4}$ Uprimny y Lasso, 2003: 112-5 
una idea de este funcionario mediante la cual los encuentros entre víctima y delincuente podrían ser útiles para ambas partes.

El experimento de Kitchener evolucionó convirtiéndose en un programa organizado para la reconciliación entre víctima y delincuente financiado con donaciones de la iglesia y subsidios del gobierno, y con el apoyo de diversos grupos comunitarios (Bakker, 1994).

Después de varias iniciativas canadienses, se lanzó el primer programa en los Estados Unidos, en Elkhart (Indiana), en 1978. Desde ese momento, los programas se han diseminado por Estados Unidos y Europa. Se estima que solo en los Estados Unidos existen 400 programas VOM, y que las cifras con similares en Europa.

\section{Las Conferencias del Grupo familiar de Nueva Zelanda}

Las CGF son una experiencia de origen neozelandés, basadas en el sistema tradicional de resoluciones de conflictos que tienen los maoríes en los casos en los que el victimario es una persona joven. Este sistema incorpora los valores de justicia maorí como por ejemplo el destacar los roles de la familia y de la comunidad.

En las CGF se tienen en cuenta a todas las personas que son víctimas de la acción y se exploran las consecuencias que ésta ha causado, no solo en la víctima directa, sino también en su familia, en la familia del ofensor y en otros posibles miembros de la comunidad igualmente victimados. Se reconoce y enfatiza el importante papel que tiene la familia en la vida de cualquier joven y la especial necesidad y apoyo que éste necesita cuando ha cometido una acción tipificada como delito.

En Nueva Zelanda este sistema se institucionaliza en 1989, en su Ley de Justicia Juvenil. Hoy es el proceso habitual de justicia, aplicándose en un $80 \%$ de todos los casos de violencia juvenil. Los únicos casos que no son derivados a este sistema son las acciones muy graves como asesinato $\mathrm{u}$ homicidio.

\section{Las Conferencias Comunitarias en Australia}

Australia recoge la filosofía de las conferencias de Nueva Zelanda para realizar programas basados en este planteamiento y no copias absolutas del modelo. Así se han desarrollado diferentes proyectos, cada cual con características propias y normalmente a nivel munici- 
pal. En cierto modo en un proceso similar al ocurrido en Norte América con los VORP.

Dentro de los diversos modelos de CGF de Australia, el desarrollado por el departamento de policía de Wagga Wagga es el que más difusión internacional ha tenido. En este sistema las conferencias son coordinadas por oficiales de policía uniformados o por personal escolar. Se considera muy adecuada la capacidad de la policía para derivar casos, así como la posibilidad de hacer advertencias formales por delitos menos graves.

El modelo Wagga Wagga se basa filosóficamente en la teoría de John Braithwaite ${ }^{5}$, denominada reintegrative shaming (vergüenza reintegradora), que enfatiza la posibilidad de cambio de comportamiento por parte del joven agresor.

El proyecto de Wagga Wagga se inicia en 1991. Limitándose al principio a delitos menores se fue expandiendo progresivamente a otras áreas competenciales, de tal modo que actualmente se aplica a menores infractores de una amplia gama de delitos contra la propiedad y de lesiones.

En las conferencias australianas participan órganos de gobierno local, regional y federal; así, encontramos que en ellos toman parte personas pertenecientes a escuela, policía, iglesia, departamentos de servicios sociales, departamentos de salud, industrias, negocios privados y representes de organizaciones privadas de ciudadanos.

\section{Los Círculos comunitarios (círculo sentenciador o sentencias circulares)}

Los Círculos tuvieron su origen en las comunidades indígenas de los Estados Unidos donde se utilizaba para resolver o tratar diferentes asuntos, entre ellos cuando se presentaban dificultades en la comunidad por la comisión de un comportamiento de un de sus miembro en contra de sus reglas de convivencia que ofendía a otros integrantes de la tribu'.

\footnotetext{
${ }^{5}$ Braithwaite, J. 1989. Crime, Shame and Reintegration. New Yor: Cambridge University Press.

${ }^{6} \mathrm{Su}$ adaptación para su uso en el sistema de justicia penal se desarrolló durante los ochenta, dado que los pueblos de las Primeras Naciones de Yukón y funcionarios judiciales locales intentaron desarrollar mayores vínculos entre la comunidad y el sistema de justicia formal. En 1991, el juez Barry Stuart del Tribunal Territorial de Yukón introdujo el círculo de sentencia, como un modo de compartir con la comunidad el proceso mediante el cual se imparte la justicia.
} 
Una de las aplicaciones es el Círculo Holístico de Sanación de la Comunidad de las Primeras Naciones de Hollow Water que fue utilizado para controlar y ayudar a la comunidad con los problemas originados por el alcoholismo en esa comunidad. Por su desarrollo y éxito se fue implementando para solucionar los casos de daños originados en comisión de un delito, buscando sanar física y espiritualmente tanto al delincuente como a la víctima y recuperar esas personas para la comunidad. Como en los procesos de mediación y los programas de restauración, los círculos de sentencia, ofrecen un espacio de encuentro entre víctima y delincuente, pero van más allá de eso, involucrando a la comunidad en el proceso de toma de decisiones.

\section{Los Paneles Juveniles en Inglaterra y Estados Unidos}

Los Paneles se componen por dos miembros entrenados de la comunidad, uno que actúa como presidente y otro como profesional. Los paneles son atendidos por la persona joven y un padre o guardián. La víctima, de haber alguna, y una persona que pueda tener una buena influencia en la persona joven también son invitados. El Panel decide un plan de acción a través del cual el joven pueda reparar o solucionar sus problemas. Se reúne de nuevo al final de la orden para evaluar el progreso. El nivel de participación de la víctima ha sido hasta ahora escaso.

El Equipo de Delincuentes Juveniles de Oxfordshire «El YOT» ${ }^{7}$ tiene como meta consultar en cada caso a la víctima ofreciendo una oportunidad de contacto con el delincuente joven, o la oportunidad de decidir el enfoque de su reparación; el objetivo de YOT es que la preparación forme parte de la sentencia de cada joven delincuente. Las víctimas que no quieren reunirse con el delincuente joven o recibir reparación pueden elegir en qué proyecto reparador local quieren que el delincuente participe. Al actuar como mentores para delincuentes jóvenes, el rol de los supervisores es crucial. La guía se personaliza en función de las necesidades individuales del delincuente, separando al joven de sus amigos e influencia de compañeros. Un elemento especialmente positivo del esquema YOT es el énfasis en que la reparación sea visible para la sociedad. Al buscar involucrar a la comunidad, el YOT distribuye un boletín de noticias de reparación para profesionales interesados y realiza juntas públicas para celebrar $\operatorname{logros}^{8}$.

\footnotetext{
${ }^{7}$ Oxfordshire es un condado no metropolitano al sureste de Inglaterra.

${ }^{8}$ Fuentes: Home Office, 2003.
} 


\section{Mediación penal víctima-infractor}

Es un proceso en el que la víctima y el infractor se reúnen cara a cara (si es posible) con un mediador.

Los programas de mediación víctima-delincuente (también conocidos como programas de reconciliación víctima-delincuente) se encontraban entre las primeras iniciativas de justicia restaurativa. Estos programas pueden ser dirigidos por agencias gubernamentales y organizaciones sin ánimo de lucro y están generalmente restringidos a casos de delitos menos graves. Pueden operar en el juicio pre-sentencia, post-sentencia/pre-juicio y post-juicio y requieren la participación activa de víctima y delincuente.

Hay más de 300 programas de mediación de víctima e infractor en Norteamérica, y más de 500 en Europa. Las investigaciones sobre estos programase evidencian una mayor satisfacción y menor temor en las víctimas que han participado en éstos, así como una menor probabilidad de que el infractor vuelva a delinquir.

\section{LA MEDIACIÓN}

Desde principios de la década de los ochenta surgen en Europa diversas iniciativas de justicia restaurativa bajo la forma de MEDIACIÓN, que partieron del Consejo de Europa, y posteriormente de la Unión Europea. La Decisión marco del Consejo de la Unión Europea de 15 de marzo (2001/220/JAI), relativa al estatuto de la víctima en el proceso penal define la mediación como la búsqueda, antes o durante el proceso penal, de una solución negociada entre la víctima y el autor de la infracción, en la que medie una persona competente... y declara que «los Estados miembros procurarán impulsar la mediación en las causas penales [...]. Velarán para que pueda tomarse en consideración todo acuerdo entre víctima e inculpado que se haya alcanzado con ocasión de la mediación».

La Recomendación (99), de 15 de septiembre de 1999 del Consejo de Europa facilita en su anexo una sencilla definición de la mediación: todo proceso que permita a la víctima y al delincuente participar activamente, si consienten libremente, en la solución de los problemas provocados por el delito, con la ayuda de un tercero independiente, el mediador. Y contiene una serie de principios generales que estructuran y dotan de sentido a la mediación: 
1. La libertad de los intervinientes en todo momento de la mediación, que se basa en su consentimiento, por ello a diferencia del proceso penal, iniciada la mediación puede concluirse en cualquier momento a solicitud de una de las partes.

La confidencialidad de las entrevistas y la imposibilidad de aprovechar en el proceso su contenido -salvo pacto en contrario- sin el acuerdo de os interesados.

2. Su consideración como servicio disponible en todas las fases del proceso penal.

3. La autonomía del mediador en el marco del sistema de justicia penal.

La denominada «justicia restaurativa», en la cual una de las principales herramientas es la mediación, se presenta como un nueva manera de afrontar la resolución de las cuestiones derivadas de la comisión de un delito, alcanzando a todas las personas implicadas, que resuelven el conflicto con el objetivo principal de la reparación de los daños, materiales o inmateriales. Se trata de una nueva visión de la justicia penal, donde la participación y las necesidades de la víctima son fundamentales, así como el sentido de la responsabilidad de la persona delincuente, con el fin de su reinserción social.

Siendo la naturaleza de la mediación, como recurso para la solución de conflictos de carácter voluntario, alternativo a la jurisdicción, subsidiario y disponible para las partes en el ámbito del derecho privado, parece absolutamente clara su viabilidad e incluso en ocasiones su oportunidad y mejor adaptación al problema, que la vía judicial ${ }^{9}$. En determinados problemas de índole contenciosa en el marco del derecho privado, como pueden ser los estereotipos de los conflictos de familia o los conflictos en materia de consumo, la mediación puede aportar una operatividad y eficacia que supere los parámetros que en este sentido pueda proporcionar el acceso a la vía judicial como medio de solución del problema.

En España la Ley 15/2005, de 8 de julio, de mediación familiar, por la que se modifican el Código civil y la Ley de Enjuiciamiento ci-

\footnotetext{
${ }^{9}$ Para un estudio pormenorizado sobre el principio de oportunidad y la conveniencia de instaurar la mediación, como alternativa a la Jurisdicción, en el proceso penal, se remite al lector a CALAZA LÓPEZ, M. S., «¿Es realmente un principio la oportunidad?», Actualidad Jurídica Aranzadi n. ${ }^{\circ}$ 842, 10 de mayo de 2012; «La subordinación de la oportunidad a la legalidad en el proceso penal», Revista Doctrinal Aranzadi n. ${ }^{\circ}$ 5, 2012; «Las paradojas del mal llamado principio de oportunidad en el proceso penal», La Ley Penal n. ${ }^{\circ}$ 103, Ed. La Ley, Madrid, 2013.
} 
vil en materia de separación y divorcio, en la que por primera vez en el ámbito procesal civil se incluyen normas concretas que albergan el sometimiento a mediación de determinadas cuestiones en materia de familia. Sin perjuicio de la regulación propia de la mediación familiar que han llevado a cabo varias Comunidades Autónomas: País Vasco mediante Ley 1/2008; Comunidad Autónoma de Madrid, mediante Ley 1/2007; Asturias mediante Ley 3/2007; Castilla y León mediante Ley 1/2006; Baleares mediante Ley 18/2006; Castilla La Mancha mediante Ley 4/2005 del Servicio social especializado en mediación familiar; Canarias mediante Ley 15/2003 de la mediación familiar; Comunidad Autónoma Valenciana mediante Ley 7/2001, reguladora de la mediación familiar; Galicia, mediante Ley 4/2001; Cataluña mediante Ley 1/2001; Posteriormente, Andalucía Ley 1/2009; Cataluña Ley 15/2009, de 22 de julio.

Posteriormente, se publica la Ley 5/2012, de 6 de julio, de medidas en asuntos civiles y mercantiles, desarrollada por el Real Decreto 980/2013 en cuatro aspectos: la formación del mediador; su publicidad a través de un Registro dependiente en el Ministerio de Justicia; el aseguramiento de su responsabilidad y la promoción de un procedimiento simplificado de mediación por medios electrónicos. No estando regulada actualmente la mediación para la resolución de conflictos penales, sin embargo, en el borrador del nuevo Código Procesal Penal se ha incluido la institución de la mediación penal en los artículos 145 y siguientes, estando prohibida tajantemente como expondremos a continuación, aun sin estar establecida en nuestro país, la mediación en asuntos de Violencia sobre la Mujer en la Ley Orgánica 1/2004, de 28 de diciembre, de Medidas de Protección Integral contra la Violencia de Género.

\section{LA MEDIACIÓN PENAL EN DELITOS DE VIOLENCIA DE GÉNERO}

El art. 44 de la Ley Orgánica 1/2004, de 29 de diciembre sobre Medidas de Protección integral contra la violencia de género enumera los supuestos de competencia de los Juzgados de Violencia sobre la Mujer en el orden penal y en el civil; en el apartado 5, después de dicha enumeración, se introduce la siguiente redacción: «En todos estos casos está vedada la mediación».

Es llamativo que se esté aparentemente prohibiendo un proceso como la mediación que no está contemplado en la actualidad en la ley, ni apenas existía en la realidad en 2004 fuera de la jurisdicción de

(C) UNED. Revista de Derecho UNED, núm. 14, 2014 
menores. Se ha debatido si esta prohibición excluye la mediación penal o sólo se refiere a la civil. En cualquier caso, parece obvio que esta referencia legal hace problemática la aplicación de la mediación ${ }^{10}$ en los procesos penales relativos a esta materia ${ }^{11}$. A pesar de que el art. 44.5 de la L. O 1/2004 de 29 de diciembre, prohíbe de manera indubitada la mediación en esa materia, personalmente yo me uno a las autorizadas y numerosas voces que han abogado por la supresión de esa limitación que no tiene justificación suficiente, si la mediación aparece correctamente enfocada y manejada por expertos conscientes de la eventual asimetría de la relación o situación de desigualdad. La prohibición absoluta me parece muy cuestionable. Con carácter general se puede afirmar que la violencia de género se ha regulado por el legislador penal de un modo que tiene poco en cuenta las posibilidades de participación de la víctima en el proceso ${ }^{12}$. Este modelo sobreprotector es desde luego coherente con la prohibición de la mediación en esta materia, al no considerar a la mujer víctima de estos delitos con capacidad para intervenir en el proceso en la búsqueda de cualquier acuerdo reparador, cuando ni siquiera puede rechazar o pronunciarse sobre la medida de alejamiento. Cuando se legisló, parece que se pensó solamente en casos en los que efectivamente había una violencia física o psíquica grave y reiterada, no teniendo en cuenta

${ }^{10}$ Recordemos que en la actualidad sólo hay una Decisión Marco del Consejo de la Unión Europea de 15 de marzo de 2001 (2001/220/JAI), relativa al Estatuto de la Víctima en el proceso penal que establece: «Los Estados Miembros procurarán impulsar la mediación en las causas penales.... Velarán para que pueda tomarse en consideración todo acuerdo entre víctima e inculpado que se haya alcanzado con ocasión de la mediación...»

${ }^{11}$ Vid, ESTIRADO DE CABO, «Cuestiones relevantes de derecho sustantivo y procesal respecto de la incorporación de la mediación a la jurisdicción penal de adultos en las fases de instrucción y de enjuiciamiento» dentro de La mediación civil y penal. Un año de experiencia. Estudios de derecho judicial 136-2007, Centro de documentación judicial, CGPJ, Madrid, 2008, pág. 212 y s.

${ }^{12}$ Vid., sobre esta cuestión, LUACES GUTIÉRREZ, A. I., «Cuestiones controvertidas en torno a la competencia penal de los Juzgados de violencia sobre la mujer», en De Hoyos Sancho, Montserrat (Dir.), Tutela jurisdiccional frente a la violencia de género. Aspectos procesales, civiles, penales y laborales, Editorial Lex Nova, Valladolid, 2009; «La mujer inmigrante víctima de violencia de género: especial referencia al Derecho a la información, a la protección social integral y a la asistencia jurídica gratuita», en Castillejo Manzanares (Dir.), Alonso Salgado (Coord.), Violencia de Género y Justicia, Universidad de Santiago de Compostela, 2013; "Necesidad de una justicia especializada en violencia de género: especial referencia a los Juzgados de violencia sobre la mujer», RDUNED. Revista de Derecho UNED, núm. 4, 2009; "Consideraciones criticas en torno a la competencia civil de los Juzgados de Violencia sobre la Mujer», Justicia. Revista de Derecho Procesal, núm. 3-4, 2011; «La exención del deber de declarar de las víctimas de violencia de género", Práctica de Tribunales. Revista especializada en Derecho procesal civil y mercantil, núm. 101, año 10, marzo-abril de 2013. 
que existen otro tipo de acciones que sí podrían ser tratadas a través del cauce de la mediación penal ${ }^{13}$.

Es opinión mayoritaria la que apunta que en los delitos de violencia de género hay en principio un desequilibrio de poder y emocional entre las partes, cosa que no comparto en su totalidad, pero hay que tener en cuenta que existe una gran diversidad de situaciones, desde delitos de gran levedad tanto por su escasa intensidad en la lesión del bien jurídico, como por su carácter puntual y aislado en la relación de pareja, hasta delitos que se enmarcan en una situación sistemática de dominación machista, pasando por todas las posibles situaciones intermedias ${ }^{14}$, sin embargo la ley penal contempla esta realidad desde una visión muy rígida ${ }^{15}$.

También en el marco de las Naciones Unidas se ha vedado el empleo de la mediación en este campo delictivo. El último Informe del Secretario General de Naciones Unidas relativo a la violencia de género, de fecha 6 de julio de 2006, que lleva por título «Estudio a fondo sobre todas las formas de violencia contra la mujer», omite realizar mención alguna, ya sea de carácter positivo o negativo, en torno a la posibilidad de aplicar mecanismos de Justicia Restauradora a dichos supuestos de agresión contra la mujer en el ámbito doméstico. La única referencia en un sentido parecido alude a la reparación del daño causado a la víctima, como cuestión vinculada, al menos en cierta forma al planteamiento de las técnicas restauradoras, si bien, a este respecto se está pensando preferentemente en la obligación por parte del propio Estado de indemnizar dichos perjuicios. Así lo indica el subapartado $3 .^{\circ}$ del apartado C sobre «Medidas encaminadas a hacer frente a la violencia contra la mujer». Entre los recursos disponibles para estas víctimas se encuentran la reparación de los daños sufridos, la restitución, la compensación, la satis-

${ }^{13}$ Desde mi labor como Abogada, puedo afirmar con rotundidad que cuando por turno de oficio se me asigna la defensa de un imputado de violencia de género, son numerosas las veces en las que la propia víctima me pide información acerca de cómo ver a su pareja, de cómo puede retirar la orden, de cómo volver atrás, pues ella no quería nada de esto. Ha habido víctimas que incluso me han llegado a confesar que "sólo quería darle un escarmiento», "pensaba que así me darían una ayuda económica y una casa, pero no que él iría a la cárcel», "he sido yo la que le he empezado a agredir», etc.

${ }^{14}$ Vid., al respecto, CALAza LóPEz, S., «Incidencia de la violencia de género en la Jurisdicción matrimonial civil», Ed. Tirant lo blanch, 2014.

${ }^{15}$ Vid., EstiRADO DE CABO, «Cuestiones relevantes de derecho sustantivo y procesal respecto de la incorporación de la mediación a la jurisdicción penal de adultos en las fases de instrucción y de enjuiciamiento» dentro de La mediación civil y penal. Un año de experiencia. Estudios de derecho judicial 136-2007, Centro de documentación judicial, CGPJ, Madrid, 2008, pág. 213. 
facción, la rehabilitación y las garantías de no repetición y prevención). Esta situación de lege lata habría de convencernos sobre la inidoneidad en el actual contexto socio-jurídico español de cualquier tendencia a instaurar técnicas de mediación entre las partes con carácter general ${ }^{16}$.

El conflicto violento generado en el ámbito de la pareja presenta una realidad que parece superar a los poderes públicos y a cualquier política criminal. Es un conflicto social, incardinado en la propia estructura social y en lo que viene siendo su célula base, la pareja y/o familia ${ }^{17}$. Visto que el castigo no frena este tipo de conductas, deberíamos preguntarnos acerca de cuáles son las necesidades de las partes y buscar otras formas de ayuda. Si miramos al conflicto, tendremos que mirar necesariamente a las necesidades e intereses de las partes, mientras que si seguimos mirando a los hechos, sólo seguiremos haciendo hincapié en el aumento de la penalización de conductas ${ }^{18}$. Es muy llamativo que desde junio de 2007 hasta el mismo mes del año 2010, del total de denuncias presentadas, el 35\% de las sentencias sobre delitos y faltas en esta materia fuesen absolutorias. Así, mismo, también llama poderosamente la atención que durante ese período el porcentaje de renuncias una vez presentada la denuncia ascienda al $12,4 \%$ de los $\operatorname{casos}^{19}$. Estos datos plantean si realmente esta ley y estos juzgados están resolviendo los problemas de fondo de las parejas o si por el contrario, en muchos de estos casos, se podría utilizar un mecanismo alternativo al judicial, que permita resolver eficazmente el conflicto que verdaderamente subyace en las parejas para que no se llegue a la violencia.

Retomando los argumentos a los que he aludido anteriormente sobre la posibilidad de introducir la mediación penal en este tipo de delitos y para supuestos aislados que no revistan ningún tipo de gravedad, sería preciso sostener, como recoge Esquinas Valverde en su monografía titulada "La Mediación entre la víctima y el agresor en la

${ }^{16}$ Vid., Esouinas VaLVERde, Mediación entre la víctima y el agresor en la violencia de género, Tirant Lo Blanch, Valencia, 2008, pág. 17 y ss.

${ }^{17}$ Para un estudio pormenorizado y de conjunto sobre los conflictos matrimoniales, se remite al lector a CALAZA LÓPEZ, S., «Los procesos matrimoniales. Nulidad, separación y divorcio», Ed. Dykinson, Madrid, 2009; «Jurisdicción voluntaria de familia y sucesiones», Madrid, 2014, en prensa.

${ }_{18}$ PAlma ChazarRa: La mediación como proceso restaurativo en el sistema penal. Tesis Doctoral. Universidad de Sevilla. 2007. Pág. 351.

${ }^{19}$ SÁEz Rodríguez: «La estrategia penal contra la violencia de género en su complicado encaje con la mediación penal» en MARTínez Escamilla (Dir.): Justicia restaurativa, mediación penal y penitenciaria: un renovado impulso, Editorial Reus, Madrid, 2011. En prensa 
violencia de género, ¿una oportunidad o un desatino?» en la conclusión final, una doble cuestión de lege ferenda. Por una parte, habría que rechazar la aplicación de la mediación en aquellos supuestos de violencia de género que impliquen una prolongada historia de agresiones, maltrato o dominación por parte del hombre sobre su (ex) pareja femenina, pues en estas circunstancias, un proceso de acercamiento y de diálogo entre las partes resultaría excesivamente peligroso para la víctima, en la medida en que ésta se verá atrapada en una dependencia psicológica, emocional y puede que incluso social y económica respecto de su agresor, lo que disminuiría sensiblemente la probabilidad de que ambos pudieran alcanzar un acuerdo realmente justo y equitativo. Y de otra parte, estarían los episodios esporádicos y aislados, en su caso, primeros o únicos, de agresión leve o de maltrato de obra o amenazas (en algunas ocasiones mutuas), en los que el ataque físico o psicológico por parte del hombre no se integre en una larga espiral de violencia, lo que podría dar lugar a que dicho incidente fuera objeto de un trámite jurídico más rápido o expedito, quedando abierta la posibilidad de continuar con la relación afectiva. Para este tipo de casos se ha sugerido bajo ciertas condiciones, la conveniencia de realizar un proceso de mediación inserto en el sistema procesal penal ${ }^{20}$, por medio del cual fuera factible recomponer ese vínculo sentimental, atendiendo a su vez a las necesidades de cada una de las partes: de seguridad, de autoafirmación y reivindicación de sus derechos e intereses en el caso de la víctima, y de tratamiento psicológico, asunción de responsabilidad y posibilidad de solicitar y recibir perdón en el caso del autor.

\section{PROPUESTA DE MODIFICACIONES LEGISLATIVAS PARA ACOGER LA MEDIACIÓN PENAL EN LA LEGALIDAD SUSTANTIVA Y PROCESAL}

Aunque en la práctica la mediación penal es viable con las herramientas del sistema actual, es conveniente su regulación para que ésta se consolide y ofrecer mayor seguridad jurídica. De incorporarse, éstas serían, entiendo, las modificaciones que habría que introducir en nuestros textos legales ${ }^{21}$ :

\footnotetext{
${ }^{20}$ Vid., MeEFI: «Mediation bei häuslicher Gewalt?» en Revista Die Praxis des Famili en rechts. 2/2003, págs. 260 y ss.

${ }^{21}$ Vid. EsTher PASCUAL RodRíguez, «La Mediación en el sistema penal: propuestas para un modelo reparador, humano y garantista. Madrid, 2011.
} 


\section{Modificaciones de derecho sustantivo a introducir en el Código Penal:}

Primera. Necesidad de incorporar una atenuante específica al artículo $21-21.8 \mathrm{CP}$ - en los siguientes términos ${ }^{22}$ : «Será causa de atenuación de la responsabilidad penal la participación con resultado positivo en un proceso de mediación entre víctima e infractor. La ejecución material de la reparación deberá, al menos, iniciarse con anterioridad al acto del juicio oral. La reparación puede entenderse suficiente, si así lo acuerdan las partes, con la restitución, reparación, indemnización, petición de perdón, reconocimiento de hechos y otras que sean consideradas como idóneas por el/la Juez o el Tribunal, el Ministerio Fiscal y las partes personadas».

La razón de ser de esta nueva atenuante reside en que la participación del infractor en un proceso de mediación tiene mayor repercusión en la satisfacción de la víctima que la simple reparación del art. 21.5 -reparación total o parcial antes del juicio oral-. Obviamente, el reproche estatal por la infracción cometida tiene que quedar más atenuado por la participación en un proceso de mediación. La nueva atenuante podría ser aplicada como simple o muy cualificada en función de las circunstancias concurrentes en el proceso de mediación y el grado de compromiso y cumplimiento de los acuerdos a los que llegasen las personas víctima e infractora.

Segunda. En cuanto a la penalidad en las faltas, habría que modificar el art. $638 \mathrm{CP}$ en el sentido de introducir el párrafo siguiente: «En caso de que culmine el proceso de mediación penal entre las partes con un acuerdo que ponga fin a las discrepancias que les enfrentaban y que ambas estén de acuerdo, se acordará el sobreseimiento libre y posterior archivo de las actuaciones».

Tercera. Modificación del art. $80 \mathrm{CP}$, incorporando un nuevo apartado -80.5 CP- en los siguientes términos: «Los Jueces y Tribunales podrán otorgar la suspensión de las penas de prisión de hasta tres años aunque no concurra el requisito del art. 81.1» $\mathrm{CP}$, en el caso de conciliación entre víctima e infractor a través de un proceso de mediación en cualquiera de las fases del proceso, siempre que no se haya procedido al archivo de las actuaciones.

${ }^{22}$ Algunas de estas propuestas están incluidas en la obra de Ríos MARTín, PASCUAL RodríGUEZ, BIBIANo GUILlÉn y SEgOVIA BERNABÉ, La mediación penal y penitenciaria. Experiencias de diálogo en el sistema penal para la reducción de la violencia y el sufrimiento humano, 2. ${ }^{\mathrm{a}}$ ed., Colex, 2008, páginas 138-146. Fueron elaboradas por los autores del libro y por Félix Pantoja cuando era Vocal del CGPJ. 
El objetivo de esta nueva norma es incentivar la participación en el proceso de mediación, incluso con posterioridad a la sentencia.

Cuarta. Modificación del art. 57.2 CP el cual dispone «En los supuestos de los delitos mencionados en el primer párrafo del apartado 1 de este artículo cometidos contra quien sea o haya sido cónyuge, o sobre persona que esté o haya estado ligada al condenado por una análoga relación de afectividad aun sin convivencia, o sobre los descendientes, ascendientes o hermanos por naturaleza, adopción o afinidad, propios o del cónyuge o conviviente, o sobre persona amparada en cualquier otra relación por la que se encuentre integrada en el núcleo de su convivencia familiar, así como sobre las personas que por su especial vulnerabilidad se encuentran sometidas a su custodia o guarda en centros públicos o privados, se acordará EN TODO CASO, la aplicación de la pena prevista en el apartado 2 del artículo 48 por un tiempo que no excederá de diez años si el delito fuera grave o de cinco si fuera menos grave, sin perjuicio de lo dispuesto en el párrafo segundo del apartado anterior».

Esta medida debería ser opcional apreciándose en el caso concreto, dejándolo para delitos más graves, y valorativos en caso de delitos menos graves y sobre todo para las faltas.

Quinta. Modificación del art. 48.2 CP que dispone «La prohibición de aproximarse a la víctima, o a aquellos de sus familiares $\mathrm{u}$ otras personas que determine el juez o tribunal, impide al penado acercarse a ellos, en cualquier lugar donde se encuentren, así como acercarse a su domicilio, a sus lugares de trabajo y a cualquier otro que sea frecuentado por ellos, quedando en suspenso, respecto de los hijos, el régimen de visitas, comunicación y estancia que, en su caso, se hubiere reconocido en sentencia civil hasta el total cumplimiento de esta pena».

Esta medida debería ser, al igual que en el caso anterior opcional, apreciándose para el caso concreto y, dejándolo para delitos más graves, y a valorar en caso de delitos menos graves y sobre todo para las faltas.

\section{Modificaciones de Derecho sustantivo a modificar el artículo 44.5 de la Ley Orgánica de Medidas de protección Integral contra la violencia de género (1/2004):}

Según el artículo 44.5 LO 1/2004, «En todos los estos casos está vedada la mediación». Esta prohibición debería ser opcional y valorada en cada concreto. 
Habría de introducirse la institución de la mediación puesto que las cargas familiares implicadas en la mayoría de estos actos podrían beneficiarse de esta herramienta.

\section{Modificaciones de Derecho procesal a introducir en la Ley de Enjuiciamiento criminal:}

Primera. Incorporar al art. 2 LECrim un párrafo segundo en el que se incluya la definición de mediación en los siguientes términos: se trata de un proceso voluntario -técnicamente conducido por una tercera persona imparcial y neutral, denominada «mediador»- por virtud del cual el autor de una falta o delito y quien lo ha sufrido o iba a sufrirlo acuerdan a través del diálogo el modo de reparar material o simbólicamente el daño causado». Dicho proceso podrá llevarse a cabo tanto en la fase de instrucción, enjuiciamiento o ejecución en su caso.

Segunda. Ampliar la competencia de los Jueces y Tribunales. A estos efectos habría que añadir un nuevo párrafo al art. 9 LECrim en los siguientes términos: «Igualmente, serán competentes para autorizar las actividades de mediación entre las partes del proceso penal, y, en su caso, incorporar al proceso los acuerdos obtenidos y el reconocimiento de la eficacia e los mismos, conforme a lo establecido en la Ley».

Tercera. Desarrollar la actuación judicial en la fase de instrucción. A tales efectos se podría redactar el art. 325 LECrim en los siguientes términos: «El Juez de Instrucción podrá autorizar la mediación penal con el fin de que las partes puedan llegar a un acuerdo de reparación. La mediación se llevará a cabo conforme a las siguientes reglas:

1. Incoadas diligencias previas de los arts. 774 y ss. de la LECrim por el Juzgado de Instrucción, el/la Juez, con acuerdo del Ministerio Fiscal, podrá resolver someter el proceso a la mediación penal conforme a lo establecido en el art. 9 de esta Ley, en cuyo caso, en la primera declaración en calidad de persona imputada, se informará a ésta de forma sucinta de la posibilidad de someter el proceso a la mediación penal. Sin perjuicio de que, en cualquier momento de la tramitación de las Diligencias Previas el/la Juez, de oficio o a solicitud del Ministerio Público, de la víctima, persona imputada o de sus representantes legales, pueda resolver someter el procedimiento a la mediación. 
A estos efectos, en cuanto conste la designación de Letrado/a para la persona imputada, se informará a éste igualmente de la posibilidad de la mediación, para lo cual, en aquellos casos en que se estime necesario, la persona imputada podrá entrevistarse de forma reservada con su Letrada/o a fin de que le informe del proceso a seguir y de las consecuencias de la mediación. Si éste aceptara se dictará providencia acordando el inicio del mismo en la que se indicarán las razones que avalan la decisión de derivación a la mediación.

2. De dicha resolución se dará traslado a las partes personadas y al imputado por tres días. La notificación a la víctima incluirá un documento explicativo del proceso, objetivos y consecuencias de la mediación.

3. A tal fin, y una vez oídos la representación de las partes, la oficina judicial remitirá al equipo mediador la providencia de derivación, copia de la denuncia, atestado, declaraciones, escritos de calificación provisional, en su caso, así como los informes periciales que contengan algún dato de relevancia: patologías, adicciones, lesiones, tasación de daños a los efectos de determinar la cuantía de la reparación.

4. En caso de que ambas partes presten su consentimiento informado para la mediación, el Juzgado, sin perjuicio de las diligencias de investigación que deba hacer y a las que está obligado por Ley, permitirá que se pueda realizar el proceso de mediación con anterioridad a dictar Auto de Procedimiento Abreviado (art. 780 LECrim.) o de transformación en juicio de faltas (art. 779 LECrim.), a fin de que el plan de reparación alcanzado por las partes pueda ser tomado en consideración por el Ministerio Fiscal en su escrito de conclusiones provisionales.

5. Si la víctima fuese menor de edad, necesariamente tiene que acudir acompañada de su representante legal. En caso de desigualdad de criterio entre el/la menor y su representante legal, prevalecerá la decisión de la persona menor de edad. El mismo criterio se seguirá cuando la víctima sea una persona judicialmente incapacitada.

6. Concluido el proceso de mediación el equipo mediador emitirá un informe sobre el resultado positivo o negativo de la actividad mediadora acompañando, en caso de que sea positivo, el acta de reparación con los acuerdos a los que hayan llegado las partes firmada por las mismas y representantes legales de alguna de ellas si los hubiere, entregándose una copia a cada una 
de ellas. La víctima podrá ratificar judicialmente el acta de reparación si la misma lo solicita y siempre que no sea necesaria su presencia en el acto del juicio oral a petición del Ministerio Fiscal.

7. De dicho informe se dará traslado a las partes, para audiencia por 3 días, incorporando el mismo a las actuaciones.

8. Remitido el acta de acuerdo y si se hubiese finalizado la práctica de diligencias informativas necesarias, el Juzgado de Instrucción dictará Auto de Procedimiento Abreviado, con traslado a las partes a fin de que procedan conforme al art. 780 de la LECrim.

9. En caso de formular escrito de acusación, y a fin de valorar penológicamente el acuerdo alcanzado, podrá plantearse por el Ministerio Público, por el/la Letrado/a de la defensa y de la acusación particular, en su caso, que se proceda conforme a lo dispuesto en el art. 784.3 de la LECrim., bien mostrando la defensa su conformidad con el escrito de calificación del Ministerio Fiscal o redactando nuevo escrito conjunto de calificación en el que se recojan los términos del acuerdo alcanzado y las variaciones que procedan en la calificación y valoración penológica de los hechos.

Cuarta. Permitir la mediación en el juicio de faltas. A estos efectos al art. 962 LECrim se le añadirá un nuevo párrafo con el siguiente contenido:

«Si por el Juzgado se hubiera incoado juicio de faltas o se hubiese dictado Auto de transformación en faltas, a la vista de la naturaleza de los hechos, corresponderá al Juez, con acuerdo del Ministerio Público, someter la cuestión al proceso de mediación. Sin perjuicio del derecho de las partes a solicitarlo por si o por medio de su Letrado/a. Si la persona denunciada y, en su caso, su Letrado/a mostrase su buena disposición inicial a la mediación, se procederá de forma semejante al trámite de Diligencias Previas. Por el Juzgado se dictará providencia comunicando a las partes el sometimiento del proceso a la mediación y la intervención del Equipo de mediación a tales efectos.

El Juzgado de Instrucción, a fin de facilitar el proceso de mediación y dentro de los plazos legalmente establecidos, a fin de impedir la prescripción de la falta, dilatará el señalamiento para acto de juicio en espera de la finalización del proceso.

Concluido el proceso de mediación el equipo mediador emitirá un informe sobre el resultado positivo o negativo de la actividad media- 
dora, acompañando, en su caso positivo, el acta de reconciliación con los acuerdos a los que hayan llegado las partes, firmada por las mismas y representantes legales de alguna de ellas si los hubiere, entregándose una copia a cada una de ellas, y al Juzgado de Instrucción, quien lo remitirá al Ministerio Fiscal a efectos de notificación.

Sin más trámite, y de conformidad con lo establecido en el art. $638 \mathrm{CP}$, se dictará auto de sobreseimiento libre y se procederá al archivo de las actuaciones, si ese fuera el acuerdo al que las partes hubieran llegado».

Quinta. Permitir la unión del acta de reparación al sumario ante la conclusión de éste. A tales efectos se podría añadir un párrafo al artículo 622 en los siguientes términos: «de igual modo, el Juez mandará la unión al sumario del acta de reparación alcanzado conforme a las reglas del artículo 325 LECrim».

Sexta. Regular las consecuencias del acuerdo de mediación en el desarrollo del juicio oral. A tales efectos se añadiría un párrafo en el art. 689 LECrim en los siguientes términos:

«El Juez de lo Penal procederá a dictar Auto de admisión de pruebas y señalamiento de juicio oral, citando al Ministerio Fiscal y a las partes (acusado, víctima y sus representantes procesales). No se citará al mediador ni a los testigos, ni peritos propuestos y admitidos, salvo que el Ministerio Fiscal o la representación procesal de las partes manifiesten la necesidad de su presencia, de todos o algunos, en el acto del juicio oral si la mediación es parcial respecto a los hechos imputados.

Si en la causa hubiera acuerdo de mediación, el Juez preguntará a las partes, si están de acuerdo con la misma, y en caso afirmativo se procederá conforme establece el artículo 742 de esta Ley. En caso contrario, si alguna parte mostrara su disconformidad con la conciliación, se dispondrá lo que proceda en cuanto a la continuación del juicio o la remisión al instructor para concluir la instrucción, conforme establece el artículo 631 de esta Ley, expresando las actuaciones que deben practicarse».

Séptima. Incorporación de la valoración del acuerdo de mediación a la sentencia. A tales efectos se redactará un nuevo párrafo en el artículo 742 LECr en los siguientes términos: «De igual modo se resolverá conforme al acuerdo de mediación aceptado por las partes al inicio del mismo».

Octava. Incorporación de la mediación en el procedimiento abreviado. A tales efectos, se redactará un nuevo párrafo en el art. 784 LECrim.-El Juez podrá autorizar la mediación entre las partes en el 
proceso para un acuerdo de mediación conforme establece el artículo 325 de esta ley.

Novena. Incorporación del acuerdo de mediación en las sesiones del juicio oral. A tales efectos se incorporará el art. 792.2 bis: «Si en las diligencias hubiera acuerdo de conciliación, preguntará a las partes si están de acuerdo con el mismo, procediendo en su caso conforme establecen los artículos 689 y 742 de esta Ley».

Asimismo en la fase de comparecencia de conformidad y juicio se incorporará lo siguiente. "Si no hay acuerdo, se abrirá juicio oral. Si hay acuerdo, el/la Juez o Tribunal citará a las partes y abrirá juicio oral que se iniciará con el trámite de conformidad, en la que se podrá modificar el escrito de calificación, haciendo suyos los acuerdos alcanzados en el proceso de mediación, siempre dentro de los términos de legalidad (art. 787 LECrim) y valoración de la mediación antes expuestos.

Décima. Incorporación el acuerdo de mediación a la sentencia del procedimiento abreviado. A tales efectos se incorporará al 248 LOPJ un párrafo 30: «Si hubiera acuerdo de mediación, se expresará el contenido del mismo, los aspectos más relevantes de su desarrollo y el alcance que tiene en la determinación del fallo" Asimismo se incorporará al artículo 794 LEcrim el siguiente texto: «si hubiera acuerdo de mediación se recogerá conforme establece el art. 148.3 de la LOPJ».

Undécima. Regular las consecuencias de la mediación en la faltas. A tal efecto se puede incorporar el art. 962.3 en los siguientes términos: "si en el trámite hubiera acuerdo de mediación, se procederá al sobreseimiento y archivo de lo actuado, si ese es el acuerdo al que hubieren llegado las partes».

Duodécima. Dar entrada a la mediación en la fase de ejecución. A tal efecto se añadiría un último párrafo al art. 984 LECrim. en los siguientes términos: «Si se produjese el proceso de mediación durante las fases de ejecución de la sentencia, ésta producirá los efectos previstos en las leyes».

Decimotercera. Habilitar al Fiscal el ejercicio del principio de oportunidad. A estos efectos se redactará una norma con un contenido similar al art. 41 del Código penal francés: « el fiscal queda habilitado, con carácter previo a su decisión sobre la acción pública y con el acuerdo de las partes, para recurrir a la mediación si estima que tal medida es susceptible de asegurar la reparación del daño causado a la 
víctima, de poner fin al conflicto generado por la infracción y de contribuir a la rehabilitación del autor de la misma».

Decimocuarta. Introducir en el art. 520.2 de la LECrim., un nuevo derecho recogido en la letra g: «Tiene derecho a solicitar su participación en un proceso de mediación penal».

Decimoquinta. Introducir un nuevo párrafo en el art. 110 LECrim., después del primero con la siguiente redacción: «Los ofendidos y/o perjudicados por una falta o un delito podrán solicitar que se derive la causa al proceso de mediación penal, con el fin de participar activamente en el proceso».

Decimosexta. Introducir en el art. 416 de la LECrim., sobre la dispensa a la hora de declarar, un punto nuevo: «Están dispensados de la obligación de declarar: 3. El mediador o los mediadores que hayan dirigido el proceso de mediación penal».

Decimoséptima. Regular los requisitos de los equipos de mediación y de los profesionales que los componen.

Disposición Adicional. Corresponde a las Comunidades Autónomas la determinación de los equipos mediadores que en todo caso deberán estar compuestos por un jurista, un psicólogo y un trabajador social, con formación en mediación acreditada por título expedido por Universidad Pública o Privada, conforme a las normas autonómicas reguladores. Las Comunidades Autónomas en un plazo de 6 meses a partir de la publicación en el BOE de la presente ley elaborarán las normas reguladoras.

\section{CONCLUSIONES}

Estamos asistiendo a una regulación progresiva de procesos alternativos a la vía judicial, sobre todo del instituto de la mediación, lo que evidencia resultados positivos para la sociedad en general. Pienso que en un futuro se podrá extender a los delitos de violencia de género, para aquellos supuestos menos graves, y siempre con las debidas garantías. Opino que siempre hay que buscar alternativas, no conformarnos con lo estático, sino buscar como podemos mejorar las distintas situaciones que puedan darse entre los miembros de una comunidad. No hay que descartar modelos alternativos a la judicialización de los conflictos, sobre todo, por el carácter voluntario de las partes afectadas por los mismos, de someterse a estos procesos. 


\section{BIBLIOGRAFÍA}

ARANGIO-RUIZ, Vicente. «Historia del Derecho Romano». Edit. Traducción de la segunda edición italiana por Francisco de Pelsmaeker e Ivañez. Edit. Resus,. A. 1980.

BARONA VILAR, Silvia: «Solución extrajudicial de conflictos en el ámbito empresarial: negociación, mediación y arbitraje» en GONZÁLEZ-CUÉLLAR (dir.): Mediación un método de solución de conflictos. Estudio interdisciplinar, Colex, Madrid, 2010.

BRAITHWAITE, J. 1989. Crime, Shame and Reintegration. New Yor: Cambridge University Press.

BUIGUES OLIVER, G. (1990). La solución amistosa de los conflictos en Derecho Romano: el arbiter ex compromisso. Madrid: Montecorvo, p. 250. Citados por: Gaspar, Silvia. Op. cit., p. 27.

CALAZA LÓPEZ, M. S. «Los procesos matrimoniales. Nulidad, separación y divorcio», Ed. Dykinson, Madrid, 2009.

- «¿Es realmente un principio la oportunidad?», Actualidad Jurídica Aranzadi n. ${ }^{\circ}$ 842, con ISSN 1132-0257, 10 de mayo de 2012.

- «La subordinación de la oportunidad a la legalidad en el proceso penal», Revista Doctrinal Aranzadi n. ${ }^{\circ}$ 5, 2012, ISSN 1889-4380, pp. 207 a 213.

- «Las paradojas del mal llamado principio de oportunidad en el proceso penal», La Ley Penal n. ${ }^{\circ}$ 103, Ed. La Ley, Madrid, 2013, ISBN 2254-903X.

- «Incidencia de la violencia de género en la Jurisdicción matrimonial civil», Ed. Tirant lo blanch, 2014.

— «Jurisdicción voluntaria de familia y sucesiones», Madrid, 2014, en prensa.

CASTILLEJO MANZANARES, Raquel. Violencia de Género, Justicia Restaurativa y Mediación. Directora: Coordinadora: M. ${ }^{a}$ Ángeles Catalina Benavente. Edt. La ley 2012.

ESQUINAS VALVERDE: Mediación entre la víctima y el agresor en la violencia de género, Tirant Lo Blanch, Valencia, 2008, pág. 17 y ss.

ESTIRADO DE CABO: «Cuestiones relevantes de derecho sustantivo y procesal respecto de la incorporación de la mediación a la jurisdicción penal de adultos en las fases de instrucción y de enjuiciamiento» dentro de La mediación civil y penal. Un año de experiencia. 
Estudios de derecho judicial 136-2007, Centro de documentación judicial, CGPJ, Madrid, 2008, pág. 212 y s.

FERNÁNDEZ DE BUJÁN, Antonio, «Derecho Público Romano», Recepción, Jurisdicción y Arbitraje. 10. ${ }^{a}$ edición. Thompson civitas 2007.

GIL OSUNA, Bartolomé. XV CONGRESO LATINOAMERICANO DE DERECHO ROMANO, Morelia, México, 16, 17 y 18 de Agosto de 2006.

CHRISTIE, Nils: Los conflictos como pertenencia, Ad-hoc, Buenos Aires, 1992.

- (1977). Conflicts as Property. British Journal of Criminology. 17: 1-15. htt://neopanopticum.blogspot.com/2005/11/christie-nils-losconflictos-como.html.

LUACES GUTIÉRREZ, A. I. «Cuestiones controvertidas en torno a la competencia penal de los Juzgados de violencia sobre la mujer», en De Hoyos Sancho, Montserrat (Dir.), Tutela jurisdiccional frente a la violencia de género. Aspectos procesales, civiles, penales y laborales, Editorial Lex Nova, Valladolid, 2009.

- «La mujer inmigrante víctima de violencia de género: especial referencia al Derecho a la información, a la protección social integral y a la asistencia jurídica gratuita», en Castillejo Manzanares (Dir.), Alonso Salgado (Coord.), Violencia de Género y Justicia, Universidad de Santiago de Compostela, 2013.

- «Necesidad de una justicia especializada en violencia de género: especial referencia a los Juzgados de violencia sobre la mujer», RDUNED. Revista de Derecho UNED, núm. 4, 2009.

- "Consideraciones criticas en torno a la competencia civil de los Juzgados de Violencia sobre la Mujer», Justicia. Revista de Derecho Procesal, núm. 3-4, 2011.

- «La exención del deber de declarar de las víctimas de violencia de género», Práctica de Tribunales. Revista especializada en Derecho procesal civil y mercantil, núm. 101, año 10, marzo-abril de 2013.

MEEFI: «Mediation bei häuslicher Gewalt?» en Revista Die Praxis des Familienrechts. 2/2003, págs. 260 y ss.

PALMA CHAZARRA: La mediación como proceso restaurativo en el sistema penal. Tesis Doctoral. Universidad de Sevilla. 2007. Pág. 351. 
PASCUAL RODRÍGUEZ, Esther. La Mediación en el sistema penal: propuestas para un modelo reparador, humano y garantista, Madrid, 2011.

RÍOS MARTÍN, PASCUAL RODRÍGUEZ, BIBIANO GUILLÉN y SEGOVIA BERNABÉ: La mediación penal y penitenciaria. Experiencias de diálogo en el sistema penal para la reducción de la violencia y el sufrimiento humano, 2. ${ }^{\mathrm{a}}$ ed., Colex, 2008, páginas 138-146.

SÁEZ RODRÍGUEZ: «La estrategia penal contra la violencia de género en su complicado encaje con la mediación penal» en MARTÍNEZ ESCAMILLA (Dir.): Justicia restaurativa, mediación penal y penitenciaria: un renovado impulso, Editorial Reus, Madrid, 2011. En prensa

SÁEZ VALCÁRCEL, Ramón, «Alternativas a la judicialización de los conflictos: la mediación. Reflexiones a partir de una experiencia» Capítulo reparación y conciliación. BARATTA, A. Criminología crítica y crítica del derecho penal, Siglo XXI editores, México, España, Argentina, Colombia, 1993.

TRAZEGNIES GRANDA, Fernando. 1989. «Los conceptos y las cosas: Vicisitudes peruanas de la Cláusula Compromisoria y del Compromiso Arbitral», p. 543. En «El Arbitraje en el Derecho Latinoamericano y Español», Libro homenaje a Ludwik Kos Rabcewicz Zubkowsky. Lima: Cultural Cuzco, S. A.). 